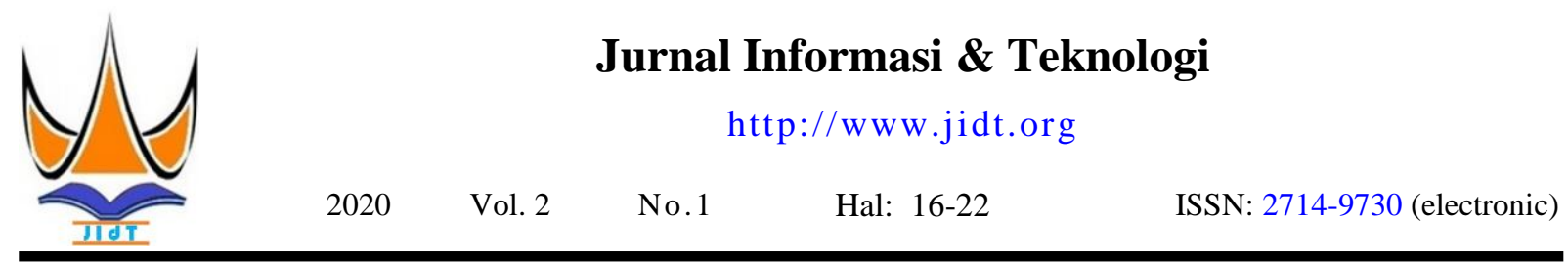

\title{
Implementasi Metode Elimination Et ChoixTraduisant La Realite (ELECTRE) dalam Penentuan Pegawai Berprestasi
}

\author{
Vera Delmayanti ${ }^{1 凶}$, Yuhandri Yunus ${ }^{2}$, Julius Santony ${ }^{3}$ \\ ${ }^{1,2,3}$ Universitas Putra IndonesiaYPTK Padang \\ verade1mayanti05@gmai1.com
}

\begin{abstract}
The Kerinci Regency Cooperatives, Industry and Trade Office has a variety of employees whose competencies in their fields are for that purpose in improving an employee's performance by determining outstanding employees who aim to motivate and reward them for improving employee work performance. In determining this outstanding employee the data used are 3 samples of employee names as alternatives and some of the criteria on which decisions are made include Service Orientation, Integrity, Commitment, Discipline, and Cooperation. The results of the process of the ELECTRE method is to compare one employee with another employee and provide the results of priority value output in the form of assessment results or based on criteria that have been determined by the Office. The results of this process are recommended as outstanding employees at the Kerinci Regency Cooperatives, Industry and Trade Office.
\end{abstract}

Keywords: ELECTREE Method, Outstanding, Employees, PHP, MySQL

\begin{abstract}
Abstrak
Dinas Koperasi, Perindustrian dan Perdagangan Kabupaten Kerinci memiliki berbagai pegawai yang kompetensi di bidangnya untuk itu dalam meningkatkan kinerja seorang pegawai dilakukan dengan menentukan pegawai berprestasi yang bertujuan untuk memotivasi dan memberikan penghargaan demi peningkatan performasi kerja pegawai. Dalam penentuan pegawai berprestasi ini data yang digunakan adalah 3 sampel nama pegawai sebagai alternatifnya dan beberapa kriteria yang menjadi dasar pengambilan keputusan antara lain adalah Orientasi Pelayanan, Integritas, Komitmen, Disisplin, dan Kerjasama. Adapun hasil proses dari metode ELECTRE ini yaitu membandingkan pegawai satu dengan pegawai yang lainnya dan memberikan hasil output nilai prioritas berupa hasil penilaian atau berdasarkan kriteria yang telah di tentukan oleh pihak Dinas tersebut. Hasil proses ini direkomendasikan sebagai pegawai berprestasi pada Dinas Koperasi, Perindustrian dan Perdagangan Kabupaten Kerinci..
\end{abstract}

Kata kunci: Metode ELECTRE, Pegawai, Berprestasi, PHP, MySQL.

\section{Pendahuluan}

Era globalisasi adalah era teknologi. Manusia mengenal teknologi yang semakin canggih. Teknologi telah dapat mempermudah pekerjaan dalam kehidupan manusia. Sistem Pendukung Keputusan (SPK) adalah informasi Peran teknologi informasi sebagai alat bantu saat ini interaktif yang menyediakan informasi, pemodelan dan sudah tidak diragukan lagi, teknologi informasi juga pemanipulasian data [2]. Metode ELECTRE adalah bisa digunakan sebagai alat bantu dalam proses salah satu metode pengambilan keputusan multikriteria pengambilan keputusan penentuan pegawai berprestasi berdasarkan pada konsep Outranking dengan dengan demikian teknologi informasi dapat menggunakan perbandingan berpasangan dari menghasilkan suatu kinerja yang lebih baik dalam alternatif-alternatif berdasarkan setiap kriteria yang perkembangan dan kemajuan suatu perusahan atau sesuai. Metode ini digunakan pada kondisi dimana intansi tersebut [1].

Sistem yang digunakan dalam menentukan pegawai berprestasi ini pada DISKOPERINDAG masih menggunakan perhitungan secara manual sehingga Keputusan adalah suatu kegiatan memilih sebuah untuk pemilihannya kurang maksimal, dan strategi atau tindakan dalam pemecahan masalah [4]. membutuhkan sistem pendukung keputusan dalam Dalam pengambilan keputusan, pengolahan data dan penentuan pegawai berprestasi dalam membantu informasi perlu dilakukan yang bertujuan untuk kendala-kendala yang ada pada sistem perhitungan menghasilkan alternatif keputusan yang dapat diambil manual. Sistem pendukung keputusan ini diharapkan [5]. Pengambilan keputusan mesti didasarkan kepada 
pertimbangan-pertimbangan logis sehingga dapat diterima oleh semua pihak yang menjadi sasaran keputusan tersebut [6]. Untuk itu dibutuhkan sebuah sistem yang dapat membantu menghasilkan keputusan Sistem pengambilan keputusan merupakan suatu sistem interaktif berbasis komputer yang ditujukan untuk membantu dalam pembuatan keputusan dengan memanfaatkan data dan model untuk menyelesaikan suatu masalah yang bersifat tidak terstruktur.

Pada dasarnya sistem pengambilan keputusan dirancang untuk mendukung seluruh tahapan pengambilan keputusan mulai dari mengidentifikasi masalah, memilih data yang relevan, menentukan pendekatan yang digunakan dalam proses pengambilan keputusan, sampai mengevaluasi pemilihan alternatif [7][8]. Sistem Pendukung Keputusan (SPK) telah banyak diterapkan untuk membantu dalam pengambilan keputusan. Hal ini terbukti dalam penelitian terdahulu yang dilakukan oleh Fauzi (2016) melakukan penelitian terhadap Sistem Pendukung Keputusan Penerimaan Bantuan Dana Rutilahu Dengan Metode ELECTRE, adapun hasil yang didapatkan adalah sistem yang dibangun dapat memabantu pengambilan keputusan pada bagian BKM (Badan Keswadayaan Masyarakat) program bantuan dana rutilahu dengan cepat dan tepat dengan hasil yang objektif dan tidak memihak pada salah satu penduduk [9]. Sedangkan Sundari dkk (2017) melakuakn penelitian terhadap Sistem Pendukung Keputusan. Hasil akhirnya dapat merekomendasikan dosen yang layak diberi penghargaan dari segi prestasi yang diperolehnya [10]. Selanjutnya Pengguna Metode ELECTRE dalam merekomendasikan paket menu makanan sesuai dengan kebutuhan energi [11] Hasil dari pengujian akurasi sistem pendukung keputusan pemilihan tanaman pangan menggunakan metode ELECTRE dan TOPSIS memiliki tingkat kesesuaian tertinggi sebesar $92.85 \%$ [12]. ELECTREE juga dapat digunakan dalam penentuan karyawan berprestasi secara tepat pada PT. Megaria Mas Sentosa [13].

\section{Metodologi Penelitian}

Pada bagian ini akan diuraikan kerangka kerja $n=$ Kriteria penelitian yang akan membantu tahap-tahap penyelesaian penelitian agar senantiasa fokus pada tujuan penelitian dan mencapai hasil yang diharapkan. Adapun kerangka kerja pada metodologi penelitian ini menguraikan tentang sistem pendukung keputusan dengan menggunakan metode ELECTRE untuk penentuan pegawai berprestasi pada Dinas Koperasi, Perindustrian dan Perdagangan Kabupaten Kerinci.

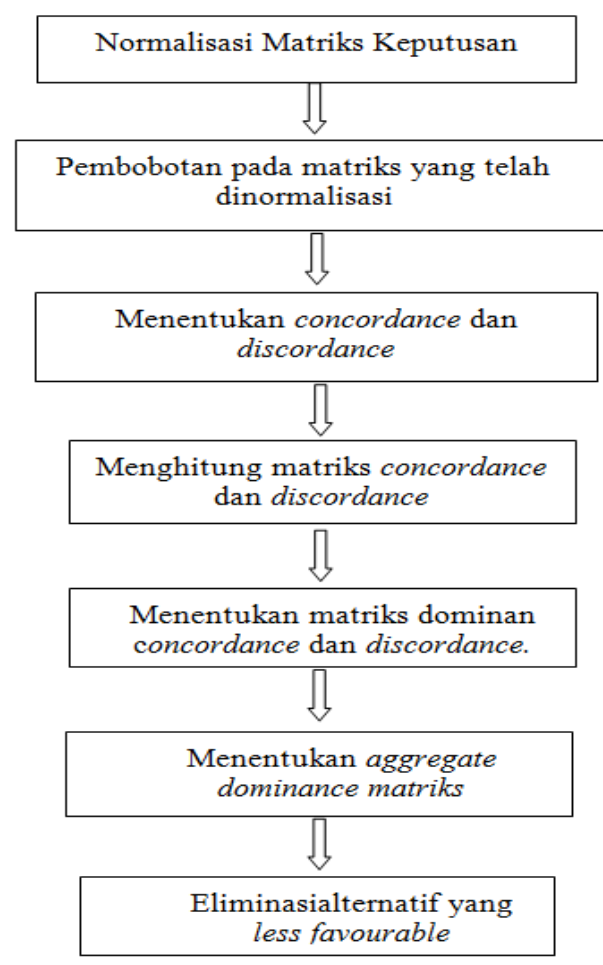

Gambar 1. Kerangka Penelitian

Pada gambar 1 dapat dilihat urutan dari proses penelitian penentuan pegawai berprestasi menggunakan metode ELECTRE.

1 Normalisasi matrik keputusan.

Setiap normalisasi $r \boldsymbol{i j}$ dapat digunakan persamaan dengan rumus :

$$
\mathrm{rij}=\frac{x i j}{\sqrt{\sum_{i}^{m}=x^{2} i j}}
$$

untuk $\mathrm{i}=1,2,3, \ldots \mathrm{m}$ dan $\mathrm{j}=1,2,3, \ldots, \mathrm{n}$

Dimana:

rij $=$ normalisasi pengukuran pilihan dari alternatif dan kriteria.

$\mathrm{m}=$ Alternatif

Sehingga didapat matriks $\mathrm{R}$ hasil normalisasi :

$$
\left[\begin{array}{llll}
\boldsymbol{r}_{11} & \boldsymbol{r}_{12} & \cdots & \boldsymbol{r}_{1 n} \\
\boldsymbol{r}_{21} & \boldsymbol{r}_{22} & \cdots & \boldsymbol{r}_{2 n} \\
\boldsymbol{r}_{m 1} & \boldsymbol{r}_{m 2} & \cdots & \boldsymbol{r}_{m n}
\end{array}\right]
$$

$\boldsymbol{R}$ adalah matriks yang telah di normalisasi atau bisa juga disebut normalizet decision matrix. Dimana $\boldsymbol{m}$ menyatakan alternatif, $\boldsymbol{n}$ menyatakan kriteria dan $\boldsymbol{r i j}$ 
adalah normalisasi pengukuran pilihan dari alternatif ke- $\boldsymbol{i}$ dalam hubungannya dengan kriteria ke- $\boldsymbol{j}$.

2. Pembobotan pada matrik yang telah dinormalisasi

Setelah dinormalisasikan, Setelah di normalisasi, setiap kolom dari matrik $\boldsymbol{R}$ dikalikan dengan bobot-bobot (wj) yang ditentukan oleh pembuat keputusan. Sehingga, wighte normalized matrix adalah $\boldsymbol{V}=\boldsymbol{R} \boldsymbol{W}$ yang ditulis dalam Rumus:

$$
V=R_{i j} W_{j}
$$

$$
\begin{gathered}
{\left[\begin{array}{cccc}
v 11 & v 12 & \ldots & v 1 n \\
v 21 & v 22 & \ldots & v 2 n \\
\ldots & \ldots & \ldots & \ldots \\
v m 1 & v m 2 & \ldots & v m n
\end{array}\right]=} \\
\mathrm{RW}=\left[\begin{array}{cccc}
\boldsymbol{W}_{1} \boldsymbol{r}_{11} & \boldsymbol{W}_{2} \boldsymbol{r}_{12} & \cdots & \boldsymbol{W}_{n} \boldsymbol{r}_{1 n} \\
\boldsymbol{W}_{1} \boldsymbol{r}_{21} & \boldsymbol{W}_{1} \boldsymbol{r}_{22} & \cdots & \boldsymbol{W}_{n} \boldsymbol{r}_{2 n} \\
\cdots & \ldots & \cdots & \ldots \\
\boldsymbol{W}_{1} \boldsymbol{r}_{m 1} & \boldsymbol{W}_{2} \boldsymbol{r}_{m 2} & \cdots & \boldsymbol{W}_{n} \boldsymbol{r}_{m n}
\end{array}\right]
\end{gathered}
$$

Dimana W adalah:

$$
\left[\begin{array}{cccc}
\mathcal{W}_{1} \boldsymbol{r}_{11} & \boldsymbol{w}_{2} \boldsymbol{r}_{12} & \cdots & \boldsymbol{w}_{n} \boldsymbol{r}_{1 n} \\
\boldsymbol{w}_{1} \boldsymbol{r}_{21} & \boldsymbol{W}_{1} \boldsymbol{r}_{22} & \cdots & \boldsymbol{W}_{n} \boldsymbol{r}_{2 n} \\
\cdots & \cdots & \cdots & \cdots \\
\boldsymbol{w}_{1} \boldsymbol{r}_{m 1} & \boldsymbol{w}_{2} \boldsymbol{r}_{m 2} & \cdots & \boldsymbol{w}_{n} \boldsymbol{r}_{m n}
\end{array}\right] \text { dan } \sum_{i}^{n}=1 \mathrm{~W}=1
$$

\section{Menentukan Concordance dan Discordance Index}

Untuk setiap pasang dari alternatif $\boldsymbol{k}$ dan $\boldsymbol{l}(\boldsymbol{k}, \boldsymbol{l}=$ $\mathbf{1 , 2 , 3 , \ldots , m}$ dan $\boldsymbol{k} \neq \boldsymbol{l}$ ) kumpulan kriteria J dibagi menjadi dua subset, yaitu concordance dan discordance. Bilamana sebuah kriteria dalam suatu alternatif termasuk Concordance adalah :

$$
C_{k l}=\left\{j, k_{k j} \geq v_{i j}\right\}, \text { untuk } j=1,2,3, \ldots, n
$$

Sebaliknya, komplementer dari subset ini adalah Discordance, yaitu apabila:

$$
D_{k l}=\left\{j, k_{k j}<v_{i j}\right\} \text {, untuk j }=1,2,3, \ldots, \mathrm{n}
$$

Dimana:
$C_{k l}=$ himpunan Concordance.

$D_{k l} \quad=$ himpunan Discordance.

$V_{k j} \quad=$ indeks dari matriks $\mathrm{V}$.

$v_{i j} \quad=$ indeks dari matriks $\mathrm{V}$.

\section{Hitung matriks Concordance dan Discordance}

\section{a. Concordance}

untuk menentukan nilai dari elemen-elemen pada matriks concordance adalah dengan menjumlahkan bobot-bobot yang termasuk dalam subset Concordance, secara matematisnya adalah pada Rumus:

$c_{k l}=\sum_{j c w} w_{j}$

Sehingga matriks Concordance yang dihasilkan adalah:

$c=\left[\begin{array}{ccccc}- & c_{12} & c_{13} & \cdots & c_{1 n} \\ c_{21} & \cdots & c_{23} & \cdots & c_{2 n} \\ \cdots & \cdots & \cdots & \cdots & \cdots \\ c_{m 1} & c_{m 2} & c_{m 3} & \cdots & -\end{array}\right]$

\section{b. Discordance}

untuk menentukan nilai dari elemen-elemen pada matriks disordance adalah dengan membagi maksimum selisih nilai kriteria yang termasuk ke dalam subsetdisordance dengan maksimum selisih nilai seluruh kriteria yang ada, secara matematisnya adalah :

$$
d_{k l} \frac{\left\{\max \left(v_{m n}-v_{m n-\mathrm{hn}}\right)\right\},_{m, n, \epsilon} d_{k l v}}{\left\{\max \left(v_{m n}-v_{\mathrm{ln}}\right)\right\},_{m, n,}=123, \ldots}
$$

Selanjutnya diperoleh matriks Discordance :

5. Menentukan matriks dominan Concordance dan Discordance

a. Concordance 
matriks dominan concordance dapat dibangun dengan ditentukan. Sistem Pendukung Keputusan penentuan bantuan nilai threshold, yaitu dengan membandingkan pegawai berprestasi ini diharapkan dapat membantu setiap nilai elemen matriks concordance dengan nilai DISKOPERINDAG dalam penentuan pegawai terbaik. threshold.

$$
c_{k l} \geq \zeta
$$

Dengan nilai threshold, adalah :

$$
\zeta=\frac{\sum_{k=1}^{n} \sum_{l=1}^{n} c_{k l}}{m^{*}(m-1)}
$$

Dan nilai setiap elemen matrik $\boldsymbol{F}$ sebagai matrik domain concordance ditentukan sebagai berikut:

$$
f_{k l}=1, \text { jika } C_{k l} \geq \varsigma \text { dan } f_{k l}=0, \text { jika } C_{k l}<\varsigma
$$

\section{b. Discordance}

Untuk Membangun matriks dominan Discordance, juga menggunakan bantuan nilai threshold, yaitu :

$$
d=\frac{\sum_{k=1}^{n} \sum_{l=1}^{n} d_{k l}}{m^{*}(m-1)}
$$

Dan nilai setiap elemen untuk matriks $\mathrm{G}$ sebagai alternatif pada kriteria yang sudah ditentukan pada matriks dominan discordanceditentukan sebagai tabel 3.. berikut:

$$
g_{k l}=1, j i k a d_{k l} \geq d \text { dan } g_{k l}=0, j i k a d_{k l}<d
$$

\section{Menentukan Aggregate dominance matriks.}

Langkah selanjutnya adalah menentukan aggregate dominance matriks sebagai Matriks $E$, yang setiap elemennya merupakan perkalian antara elemen matriks $F$ dengan elemen matriks $G$, yang sebagai berikut:

$$
e_{k l}=f_{k l} * g_{k l}
$$

\section{Eliminasi alternatif yang less favourable}

Matriks E memberikan urutan pilihan dari setiap alternatif , yaitu bila $\mathrm{E} \_\left(\mathrm{kl}=1 \text { )maka alternative } \mathrm{A} \_\mathrm{k}\right.$ merupakan alternatif yang lebih baik dari pada Al. Sehingga, baris dalam matriks E yang memiliki jumlah e_ $(\mathrm{kl}=1$ )paling sedikit dapat dieliminasi. Dengan demikian, alternatif terbaik adalah alternatif yang mendominasi alternatif lainnya.

\section{Hasil dan Pembahasan}

Sistem yang sedang berjalan saat ini, dinas belum mendapatkan hasil yang maksimal dalam pengembalian Untuk penyelesaian masalah diatas dengan keputusan. Untuk itu dibuat sistem yang baru agar lebih menggunakan metode ELECTRE akan dilakukan efektif dalam pengambilan keputusan pegawai sesuai dengan langkah-langkah yang telah dijelaskan.

\begin{tabular}{|c|c|}
\hline Alternatif & Nama Pegawai \\
\hline A1 & $\mathrm{P} 1$ \\
\hline $\mathrm{A} 2$ & $\mathrm{P} 2$ \\
\hline A3 & P3 \\
\hline
\end{tabular}
berprestasi sesuai dengan kriteria-kriteria yang telah

Berikut adalah data pegawai yang mengikuti seleksi untuk pegawai berprestasi yang menjadi alternatif untuk menjadi perhitungan dengan mengambil sampel tiga orang pegawai yang disajikan dalam tabel 1 .

Dalam proses metode ELECTRE memerlukan kriteriakriteria yang akan dijadikan bahan perhitungan dan pertimbangan dalam penyeleksian pegawai terbaik. Dalam penelitian ini terdapat 5 kriteria yang disajikan pada tabel 2 .

\begin{tabular}{|c|c|}
\hline Keterangan & Bobot W \\
\hline Orientasi Pelayanan & 1 \\
\hline Integritas & 2 \\
\hline Komitmen & 3 \\
\hline Disiplin & 4 \\
\hline Kerjasama & 5 \\
\hline
\end{tabular}

\begin{tabular}{ll} 
& Tabel 2. Kriteria \\
\hline Kriteria & Nama Pegawai \\
\hline $\mathrm{C} 1$ & Orientasi Pelayanan \\
$\mathrm{C} 2$ & Integritas \\
$\mathrm{C} 3$ & Komitmen \\
$\mathrm{C} 4$ & Disiplin \\
$\mathrm{C} 5$ & Kerjasama \\
\hline
\end{tabular}

Tabel 3. Ranting kecocokan dari setiap Alternatif

\begin{tabular}{llllll}
\hline Alternatif & \multicolumn{5}{c}{ Kriteria } \\
& C1 & C2 & C3 & C4 & C5 \\
\hline P1 & 80 & 75 & 82 & 85 & 85 \\
P2 & 77 & 88 & 90 & 88 & 88 \\
P3 & 78 & 78 & 90 & 79 & 80 \\
\hline
\end{tabular}

Pengambilan keputusan memberikan bobot preferensi yang disajikan pada tabel 4 .

Sehingga $\mathrm{W}=(1,2,3,4,5)$

Matriks keputusan yang dibentuk dari tabel kecocokan adalah sebagai berikut :

$$
\mathrm{X}=\left[\begin{array}{lllll}
80 & 75 & 82 & 85 & 85 \\
77 & 88 & 90 & 88 & 88 \\
78 & 78 & 90 & 79 & 80
\end{array}\right]
$$

Jurnal Informasi \& Teknologi Vol. 2 No. 1 (2020) 16-22 
1. Normalisasi matrik keputusan

$$
\begin{aligned}
& \left|x_{1}\right|=\sqrt{80^{2} 77^{2} 78^{2}}=135,695 \\
& r_{11}=\frac{x_{11}}{\left|x_{1}\right|}=\frac{80}{135,695}=0,5896 \\
& r_{21}=\frac{x_{21}}{\left|x_{1}\right|}=\frac{77}{135,695}=0.5675 \\
& r_{31}=\frac{x_{31}}{\left|x_{1}\right|}=\frac{78}{135,695}=0.5748 \\
& r_{32}=\frac{x_{32}}{\left|x_{2}\right|}=\frac{78}{139,474}=0,5592 \\
& r_{22}=\frac{x_{22}}{\left|x_{2}\right|}=\frac{88}{139,474}=0,6309 \\
& r_{12}=\frac{x_{12}}{\left|x_{2}\right|}=\frac{75}{139.474}=0,5377
\end{aligned}
$$$$
\left|x_{3}\right|=\sqrt{82^{2} \quad 90^{2} \quad 90^{2}}=151,407
$$$$
r_{13}=\frac{x_{13}}{\left|x_{3}\right|}=\frac{82}{151,407}=0,5416
$$$$
r_{23}=\frac{x_{23}}{\left|x_{3}\right|}=\frac{90}{151,407}=0,5944
$$$$
r_{33}=\frac{x_{33}}{\left|x_{3}\right|}=\frac{90}{151,407}=0,5944
$$

$$
\left|x_{4}\right|=\sqrt{85^{2} \quad 88^{2} \quad 79^{2}}=145,637
$$$$
r_{14}=\frac{x_{14}}{\left|x_{4}\right|}=\frac{85}{145,637}=0,5836
$$$$
r_{24}=\frac{x_{24}}{\left|x_{4}\right|}=\frac{88}{145,637}=0,6042
$$$$
r_{34}=\frac{x_{34}}{\left|x_{4}\right|}=\frac{79}{145,637}=0,5424
$$$$
\left|x_{5}\right|=\sqrt{85^{2} \quad 88^{2} \quad 80^{2}}=146,181
$$$$
r_{15}=\frac{x_{15}}{\left|x_{5}\right|}=\frac{85}{146,181}=0,5815
$$$$
r_{25}=\frac{x_{25}}{\left|x_{5}\right|}=\frac{88}{146,181}=0,602
$$$$
r_{35}=\frac{x_{35}}{\left|x_{5}\right|} \frac{80}{146,181}=0,5473
$$

Dari perhitungan diatas diperoleh $\mathrm{R}$

$\left[\begin{array}{ccccc}0,5896 & 0,5377 & 0,5416 & 0,5836 & 0,5815 \\ 0,5675 & 0,6309 & 0,5944 & 0,6042 & 0,602 \\ 0,5748 & 0,5592 & 0,5944 & 0,5424 & 0,5437\end{array}\right]$

2.Pembobotan pada matriks yang telah dinormalisasi

$$
\mathrm{V}=\mathrm{RW}
$$

$\left[\begin{array}{ccccc}0,5896 & 0,5377 & 0,5416 & 0,5836 & 0,5815 \\ 0,5675 & 0,6309 & 0,5944 & 0,6042 & 0,602 \\ 0,5748 & 0,5592 & 0,5944 & 0,5424 & 0,5437\end{array}\right]$

Dikalikan dengan nilai bobot $\mathrm{W}\left[\begin{array}{lllll}1 & 2 & 3 & 4 & 5\end{array}\right]$ Maka hasil $\mathrm{V}=\mathrm{RW}=\mathrm{V}$

$\left[\begin{array}{ccccc}0,5896 & 1,0755 & 1,6248 & 2,3346 & 2,9073 \\ 0,5675 & 1,2619 & 1,7833 & 2,417 & 3,01 \\ 0,5748 & 1,1185 & 1,7833 & 2,1698 & 2,7363\end{array}\right]$


3. Menentukan Concordance dan Discordance

a. Concordance

$\mathrm{C} 12=\{2,3,4,5\}$

$\mathrm{C} 13=\{2,3\}$

$\mathrm{C} 21=\{1\}$

$\mathrm{C} 23=\{1,3\}$

$\mathrm{C} 31=\{1,4,5\}$

$\mathrm{C} 32=\{2,3,4,5\}$

$$
C_{k l}=\left\{j, k_{k j} \geq v_{i j}\right\}
$$

b. Discordance

$\mathrm{D} 12=\{1\}$

$\mathrm{D} 13=\{1,4,5\}$

$$
D_{k l}=\left\{j, k_{k j}<v_{i j}\right\}
$$

D23 $=\{2,4,5\}$

$\mathrm{C} 31=\{2,3\}$

$\mathrm{C} 32=\{1\}$

4. Menghitung matriks Concordance dan Discordance

a. menghitung matriks Concordance

$$
c_{k l}=\sum_{j c w} w_{j}
$$

$\mathrm{C} 12=\mathrm{W} 2+\mathrm{W} 3+\mathrm{W} 4+\mathrm{W} 5=14$

$\mathrm{C} 13=\mathrm{W} 2+\mathrm{W} 3=5$

$\mathrm{C} 21=\mathrm{W} 1=1$

$\mathrm{C} 23=\mathrm{W} 1+\mathrm{W} 3=4$

$\mathrm{C} 31=\mathrm{W} 1+\mathrm{W} 4+\mathrm{W} 5=10$

$\mathrm{C} 32=\mathrm{W} 2+\mathrm{W} 3+\mathrm{W} 4+\mathrm{W} 5=14$

Jadi matriks Concordance adalah :

$$
C=\left[\begin{array}{ccc}
- & 1 & 10 \\
14 & - & 14 \\
5 & 4 & -
\end{array}\right]
$$

b. Menghitung matriks Discordance

$$
d_{k l} \frac{\left\{\max \left(v_{m n}-v_{m n-\mathrm{ln}}\right)\right\},_{m, n, \epsilon} d_{k l v}}{\left\{\max \left(v_{m n}-v_{\mathrm{ln}}\right)\right\},_{m, n,}=123, \ldots}
$$

$$
\mathrm{D}=\left[\begin{array}{ccc}
- & 1 & 0,9269 \\
0,1186 & - & 0,0269 \\
1 & 1 & -
\end{array}\right]
$$

5. Menentukan matriks dominan Concordance dan Discordance

a. menghitung matrik dominan Concordance

$$
\varsigma=\frac{14+5+1+4+10+14}{3(3-1)}=\frac{48}{6}=8
$$

Sehingga matriks dominan Concordance adalah

$$
F=\left[\begin{array}{ccc}
- & 0 & 1 \\
1 & - & 1 \\
0 & 0 & -
\end{array}\right]
$$

b. menghitung matrik dominan Discordance

$$
\begin{aligned}
D & =\frac{0,1186+1+1+1+0,9269+0,0209}{3(3-1)} \\
& =\frac{4,0664}{6}=0,6777
\end{aligned}
$$

Sehingga matriks dominan Discordance adalah

$$
G=\left[\begin{array}{ccc}
- & 1 & 1 \\
0 & - & 0 \\
1 & 1 & -
\end{array}\right]
$$

6. menentukan aggregate dominance matriks

$$
\boldsymbol{e}_{k l}=f_{k l} * \boldsymbol{g}_{k l}
$$

$$
\mathrm{F}\left[\begin{array}{ccc}
- & 0 & 1 \\
1 & - & 1 \\
0 & 0 & -
\end{array}\right] \times \mathrm{G}\left[\begin{array}{ccc}
- & 1 & 1 \\
0 & - & 0 \\
1 & 1 & -
\end{array}\right]=\mathrm{E}\left[\begin{array}{ccc}
- & 0 & 1 \\
0 & - & 0 \\
0 & 0 & -
\end{array}\right]
$$

7. Eliminasi alternatif yang les fovorable

Matriks E memberikan urutan pilihan dari setiap alternatif, yaitu bila ekl=1 maka alternatife Ak merupakan alternatif yang lebih baik dari pada Al. Sehingga, baris dalam matriks E yang memiliki jumlah ekl=lebih banyak dapat dieliminasi. Dengan demikian, P1 lebih baik dari P2 dan P3 karena memiliki angka 1 jadi pegawai terbaik adalah P1.

Jadi matriks Discordance adalah : 
Tabel 5 Rank

\begin{tabular}{cc}
\hline Nama Pegawai & Nama Pegawai \\
\hline P1 & $\mathbf{1}$ \\
P2 & 2 \\
P3 & 3 \\
\hline
\end{tabular}

\section{Kesimpulan}

Berdasarkan hasil penelitian ini penerapan metode ELECTRE dapat membantu mempermudah atasan dalam memproses penentuan pegawai berprestasi. Hasil proses ini direkomendasikan sebagai pegawai berprestasi pada Dinas Koperasi, Perindustrian dan Perdagangan Kabupaten Kerinci.

\section{Daftar Rujukan}

[1] Trisnawan, Y., (2017). Sistem Pendukung Keputusan Pemilihan Karyawan Berprestasi untuk Kenaikan Jabatan Menggunakan Metode ELECTRE (Elemination and Translition Of Reality). Artikel Skripsi Universitas Nusantara PGRI kediri, $1-9$.

[2] Sutrisno, S., Darmawan, A., \& Mustika, F. A. (2017). Sistem Pendukung Keputusan Metode Electre pada Bauran pemasaran (7P) dalam Memulai Usaha Jasa Center. STRING (Satuan Tulisan Riset Dan Inovasi Teknologi), 2(2),184-192. https://doi.org/10.30998/string.v2i2.2105.

[3] Setiawan, F., Indriani, F., \& Muliadi (2015). Implementasi Metode Electre Pada Sistem Pendukung Keputusan Snmptn Jalur Undangan, Kumpulan JurnaL Ilmu Komputer, 2(No), 197-120. https://doi .org/10.20527/klik.v2i2.29

[4] Kusuma, C. (2017). Analisis Program Restrukturisasi Kredit Macet Perbankan Dengan Menggunakan Metode Multi Atribute Utility Theory dan Vooting Copeland Score. Jurnal Ilmu Komputer dan Bisnis, 8 (1), 5234-8058.

[5] Mufid, R., \& Maslihah (2017). Sistem Pendukung Keputusan Seleksi Pemilihan Kepala Bagian Perum Damri Surabaya. Information Technologi Jurnal, 3(2), 35-40.

[6] Sabri, A. (2013). Kebijakan dan Pengambilan Keputusan Dalam Lembaga Pendidikan Islam. Jurnal Al-Ta'lim, 1(5), 373-379, https://doi .org/10. 15548/jt.v20i2.34

[7] Magdalena, H., (2012). Sistem Pendukung Kuputusan untuk menentukan Mahasiswa Lulusan Terbaik Di Perguruan Tinggi. Seminar Nasional Teknologi Informasi dan Komunikasi, 49-56, 2089-9815.

[8] Nas, C., Defit, S., \& Santony, J. (2018). Evaluasi Mutasai Jabatan Anggota Kepolisian Menggunakan Metode Profile Matching dan Multi Attribute Utility Theory. Jurnal Sains, Teknologi Dan Industri, 16(1), 30-36.

[9] Fauzi, W. (2016). Sistem Pendukung Keputusan Penerima Bantuan Dana Rutilahu dengan Menggunakan Metode Electree. Seminar Nasional Teknologi Informasi Dan Komunikasi (SENTIKA), 18-19.

[10] Sundari, S., Wanto, A., Saifullah, \& Gunawan, I. (2017). Sistem Pendukung Keputusan Dengan Menggunakan Metode Electre Dalam Merekomendasikan Dosen Berprestasi Bidang Ilmu Komputer (Study Kasus di AMIK \& STIKOM Tunas Bangsa). In Seminar Nasional Multi Disiplin Ilmu, pp. 1-6.

[11]Prakoso, T. P., \& Adi, S. S. (2015). Penggunaan Metode Electre (Elimination Et Choix Traduisant La Realite) dalam Sistem Pendukung Keputusan Menu Makanan Sehat. Jurnal Teknik Elektro, 7(1), 37-42.

[12]Mesran, M., Anita, S., \& Sianturi, R. D. (2018). Implementasi Metode Electre Dalam Penentuan Karyawan Berprestasi (Studi
Kasus: PT. MEGARIMAS SENTOSA). Jurasik (Jurnal Riset Sistem Informasi Dan Teknik Informatika), 3, 32-45. https://doi.org/10.30645/jurasik.v3i0.64

[13]Rahayu, N. P., Putri, R. R. M., \& Widodo A. W. (2018). Sistem Pendukung Keputusan (SPK) Pemilihan Tanaman Pangan Berdasarkan Kondisi Tanah Menggunakan Metode ELECTRE dan TOPSIS. Jurnal Pengembangan Teknologi Informasi dan Ilmu Komputer, 2(8), 2323-2332. 